\title{
CHARACTERIZING EXTRACTION CHROMATOGRAPHY FOR LARGE-SCALE AMERICIUM-241 PROCESSING SUPPORTING INFORMATION
}

Brian T. Arko, ${ }^{1,2}$ David Dan, ${ }^{1}$ Sara L. Adelman, ${ }^{1}$ Daniel L. Huber, ${ }^{1}$ David B. Kimball,,${ }^{1, *}$ Stosh A. Kozimor, ${ }^{1, *}$ Mila Nhu Lam, ${ }^{1}$ Veronika Mocko, ${ }^{1}$ Jenifer C. Shafer, ${ }^{2, *}$ Benjamin W. Stein, ${ }^{1}$ Sara L. Thiemann. ${ }^{1}$

${ }^{1}$ Los Alamos National Laboratory, Los Alamos, NM 87545 (U.S.A.)

${ }^{2}$ Department of Chemistry, Colorado School of Mines, Golden, CO 90401 (U.S.A.)

*Corresponding author; dkimball@lanl.gov, stosh@lanl.gov, jshafer@mines.edu 

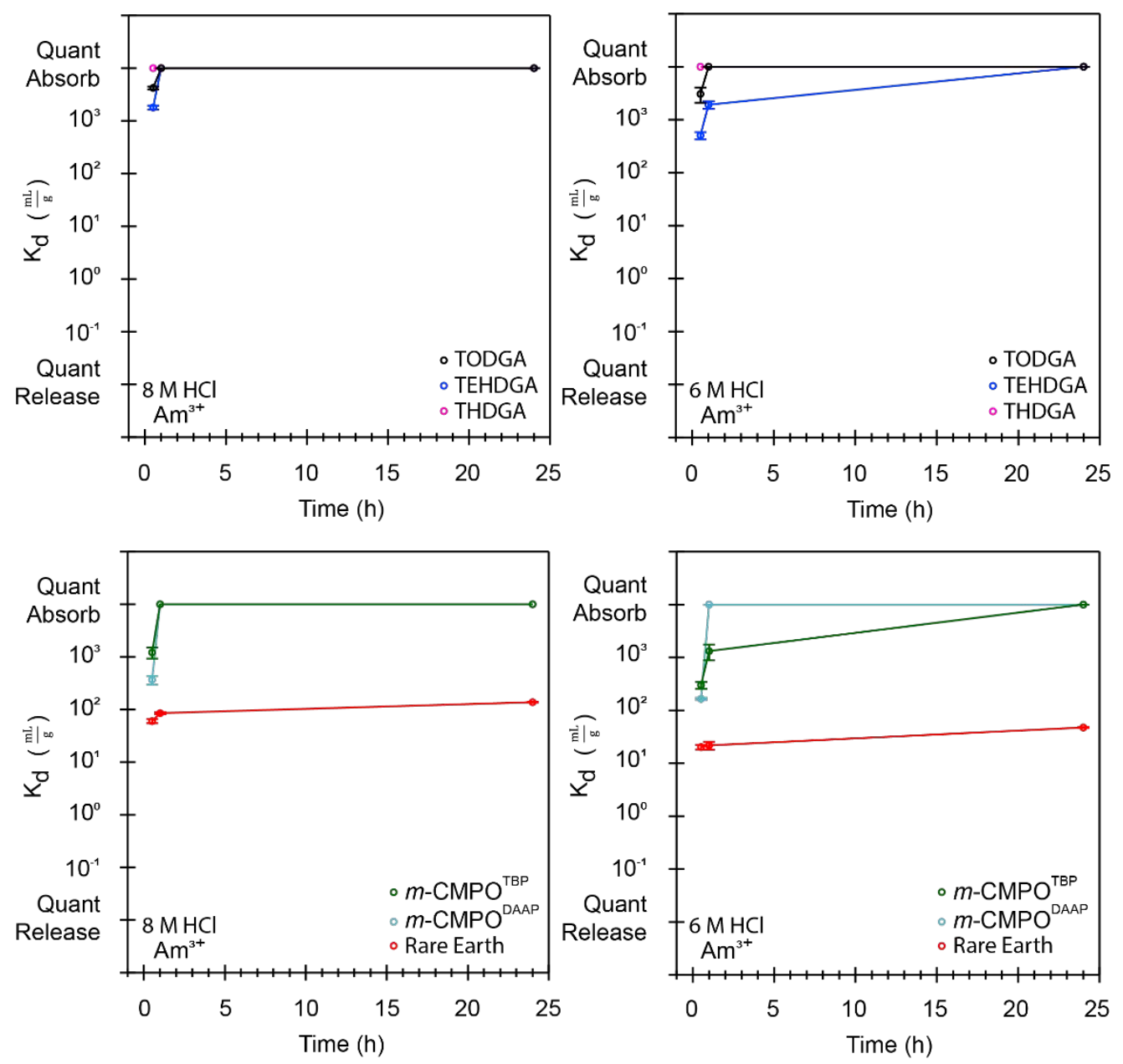

Figure S1: Temperature-controlled $\left(25^{\circ} \mathrm{C}\right)$ distribution coefficients $\left(K_{\mathrm{d}}\right)$ from ${ }^{241} \mathrm{Am}(20 \mathrm{pCi})$ made in $\mathrm{HCl}$ (left $8 \mathrm{M}$; right $6 \mathrm{M}$ ) plotted as a function of contact times. The CMPO resins [bottom; $m$-CMPO ${ }^{\text {TBP }}, m$-CMPODAAP, and Rare Earth (RE)] were compared against DGA resins (top; TODGA, TEHDGA, and THDGA). All resins utilized Pre-filter resin beads. Measurements were made in triplicate and the shown uncertainty was calculated as the standard deviation from the mean (at $1 \sigma)$. The labels "Quant Adsorb" and "Quant Release" were defined as "quantitatively adsorbed" and "quantitatively released." Timestamps are $30 \mathrm{~s}, 1 \mathrm{~h}$, and 24 h. 


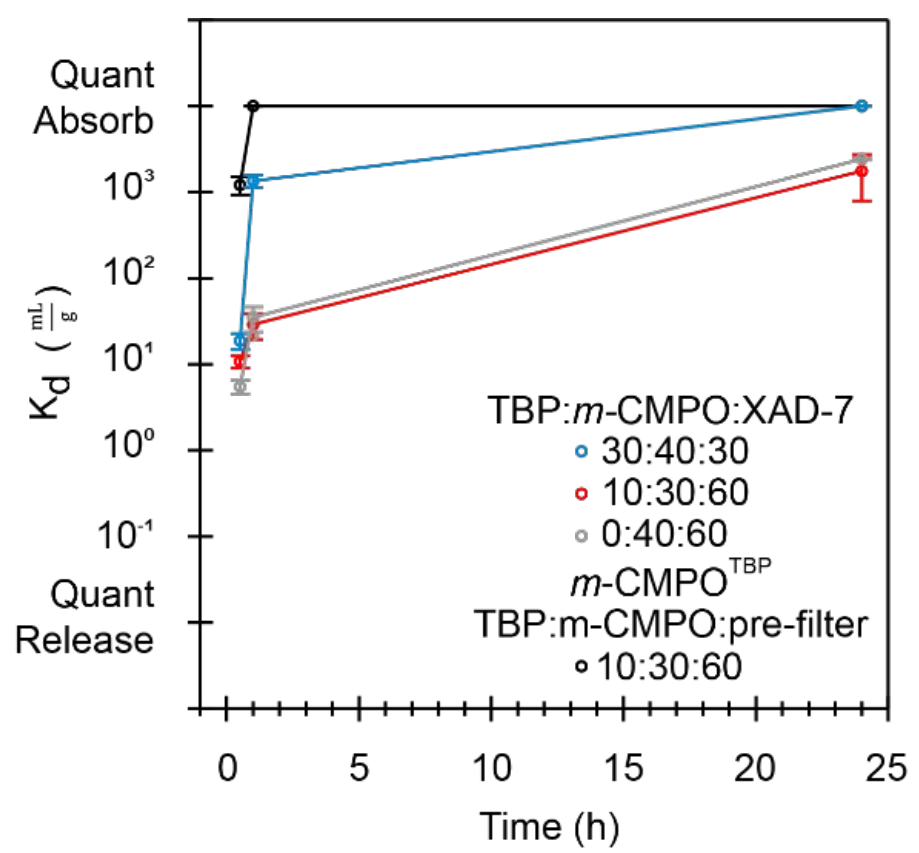

Figure S2: Temperature-controlled $\left(25^{\circ} \mathrm{C}\right)$ distribution coefficients $\left(\mathrm{K}_{\mathrm{d}}\right)$ from ${ }^{241} \mathrm{Am}(20 \mathrm{pCi})$ made in $\mathrm{HCl}(8 \mathrm{M})$ plotted as a function of contact times. The $m$-CMPO extractant was adsorbed onto large XAD-7 resin beads (2060 mesh) at various TBP loadings; TBP to $m$-CMPO to XAD-7 resin mass ratios were 0 to 40 to 60 (gray trace), 10 to 30 to 60 (red trace), and 30 to 40 to 30 (blue trace). The data were compared against the $m$-CMPO ${ }^{\text {TBP }}$ resin (black trace), which had $m$-CMPO and TBP adsorbed onto small bead containing Pre-filter resin (140-270 mesh), who's TBP to $m$-CMPO to Prefilter resin mass ratio was 10 to 30 to 60 . Measurements were made in triplicate and the shown uncertainty was calculated as the standard

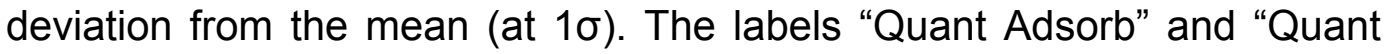
Release" were defined as "quantitatively adsorbed" and "quantitatively released." Timestamps are $30 \mathrm{~s}, 1 \mathrm{~h}$, and $24 \mathrm{~h}$. 


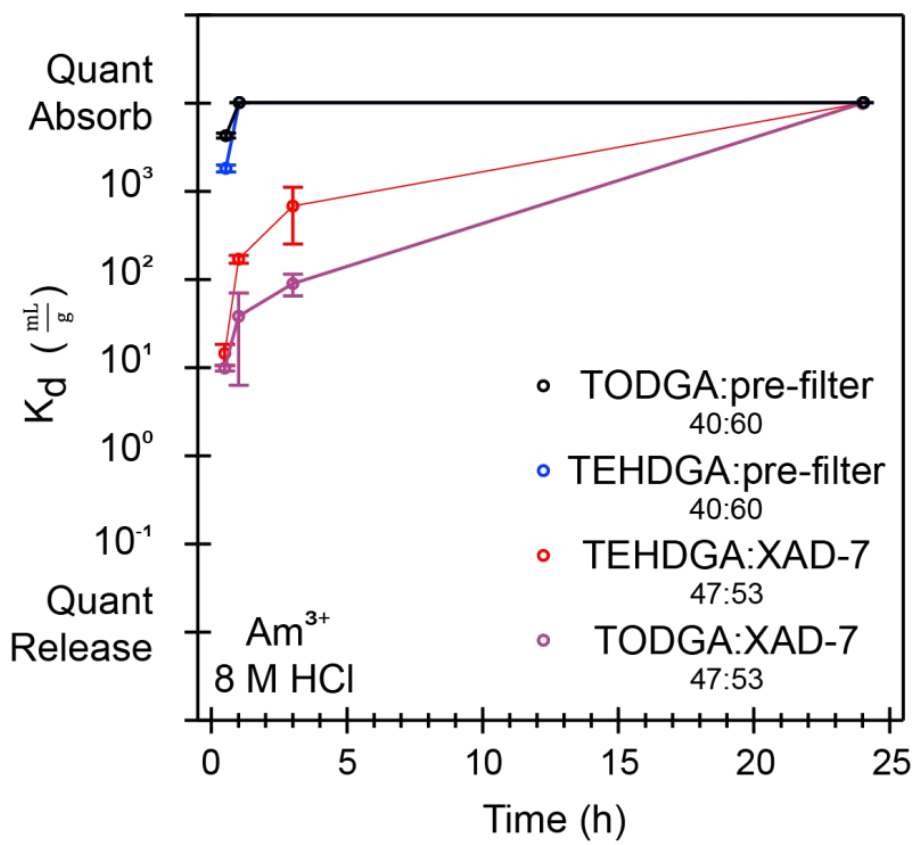

Figure S3: Temperature-controlled $\left(25^{\circ} \mathrm{C}\right)$ distribution coefficients $\left(\mathrm{K}_{\mathrm{d}}\right)$ from ${ }^{241} \mathrm{Am}(20 \mathrm{pCi})$ made in $\mathrm{HCl}(8 \mathrm{M})$ plotted as a function of contact times. The TEHDGA and TODGA extractants were adsorbed on large XAD-7 resin beads (20-60 mesh). The TEHDGA to XAD-7 resin mass ratio was 46.5 to 53.5 (red trace) and the TODGA to XAD-7 resin mass ratio was 46.6 to 53.4 (purple trace). The data were compared against resins that had TEHDGA and TODGA adsorbed onto the small bead containing Pre-filter resin (140270 mesh). The TEHDGA to Pre-filter resin mass ratio was 40 to 60 (blue trace) and the TODGA to Pre-filter resin mass ratio was 40 to 60 (black trace). Measurements were made in triplicate and uncertainty is shown as the standard deviation of the mean (at 1б). The labels "Quant Adsorb" and "Quant Release" were defined as "quantitatively adsorbed" and "quantitatively released." Timestamps are $30 \mathrm{~s}, 1 \mathrm{~h}, 3 \mathrm{~h}$, and $24 \mathrm{~h}$. 

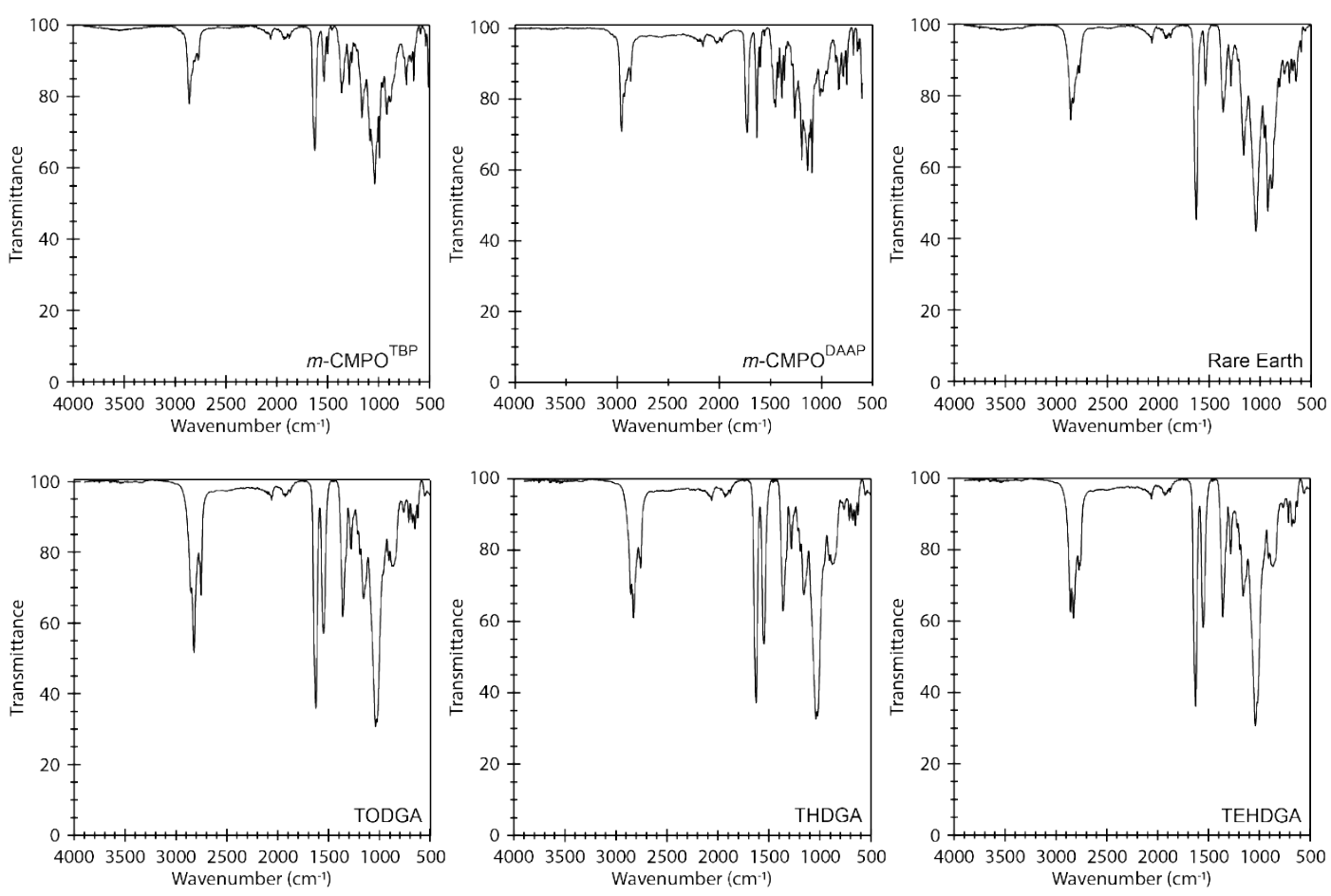

Figure S4: Infrared (IR) spectra from the most studied resins studied herein. The CMPO resins [left; m-CMPO ${ }^{\mathrm{TBP}}$, m-CMPODAP, and Rare Earth (RE)] were compared against DGA resins (right; TODGA, TEHDGA, and THDGA). All resins utilized Pre-filter resin beads. 


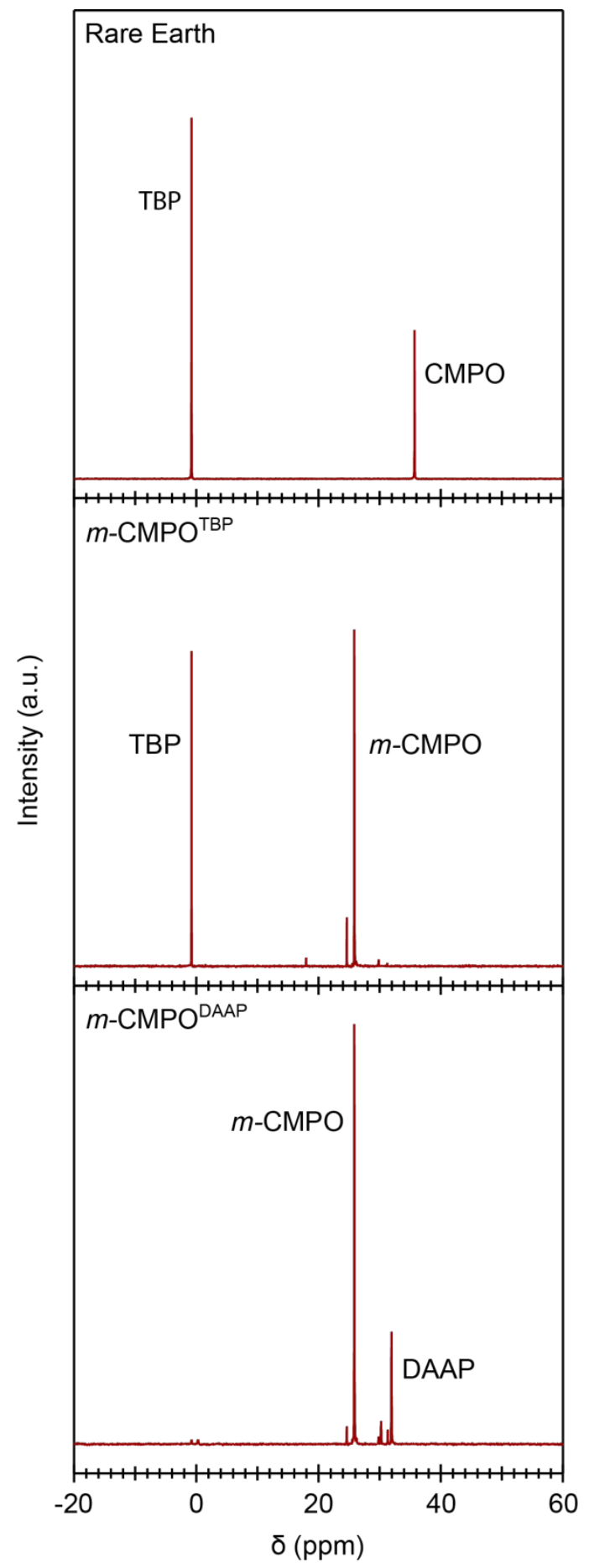

Figure S5: ${ }^{31} \mathrm{P}$ NMR spectra from CMPO and phase-transfer catalysts (TBP or DAAP) that had been striped from CMPO containing resins with DMSO$d_{6}$ [bottom, m-CMPO ${ }^{\text {DAPF; }}$ middle, m-CMPODAAP; top, Rare Earth (RE)]. All resins utilized Pre-filter resin beads. 


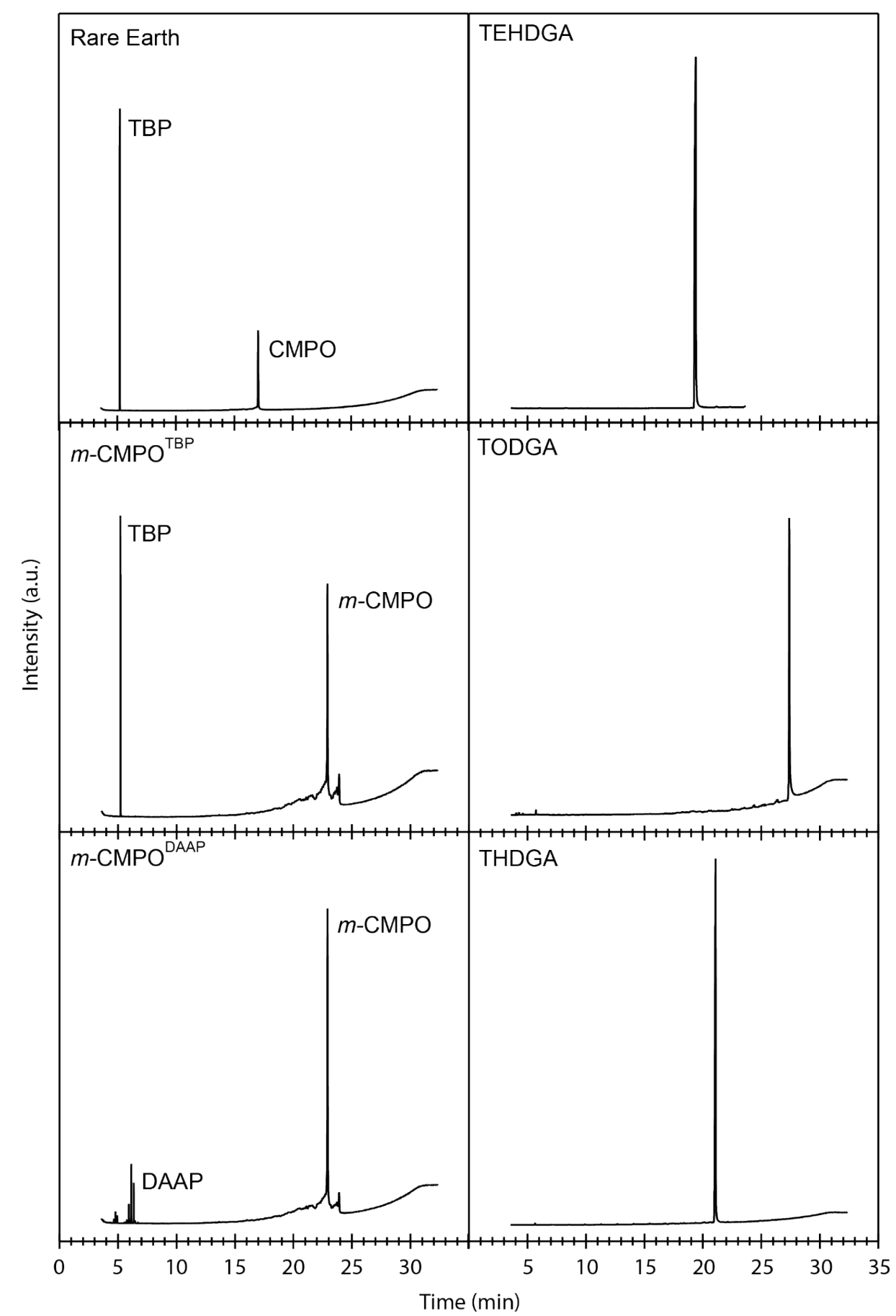

Figure S6: GCMS chromatograms from extractants and phase transfer catalysts that had been stripped with ethyl acetate from the best preforming resins studied herein. The CMPO resins [left; Rare Earth (RE), m-CMPOTBP, and m-CMPODAP] were compared against DGA resins (right; TEHDGA, TODGA, and THDGA). All resins utilized Pre-filter resin beads. 